\title{
Are Hylobates lar Extirpated from China?
}

\author{
Cyril C. Grueter • Xuelong Jiang • Roger Konrad • \\ Pengfei Fan • Zhenhua Guan • Thomas Geissmann
}

\begin{abstract}
The Nangunhe Nature Reserve in Southwest Yunnan (PRC) has long been presumed to be the last stronghold of lar (or white-handed) gibbons (Hylobates lar) in China and the likely last place of occurrence of Hylobates lar yunnanensis. We conducted a comprehensive survey to assess the status of lar gibbons at Nangunhe. We found no visual or auditory evidence of them still residing at the reserve and therefore tentatively conclude that lar gibbons have become extinct in China. It appears that large-scale destruction of primary forests in the 1960s and 1970s brought about an initial decline in their numbers, and subsequent uncontrolled hunting has resulted in their extirpation. The situation for the six Chinese ape taxa is nothing less than disastrous, with 1 taxon assumed to have become extinct during the last few years, 1 taxon not having been confirmed since the 1980s, and 2 species at the very brink of extinction with only tens of individuals remaining in China.
\end{abstract}

C. C. Grueter $(\bowtie) \cdot$ T. Geissmann

Anthropological Institute, University of Zürich, 8057 Zürich, Switzerland

e-mail: cyril_grueter@eva.mpg.de

C. C. Grueter $\cdot$ R. Konrad • T. Geissmann

Gibbon Conservation Alliance, Anthropological Institute, University of Zürich,

8057 Zürich, Switzerland

C. C. Grueter

Jane Goodall Institute, Anthropological Institute, University of Zürich, 8057 Zürich, Switzerland

X. Jiang $\cdot$ Z. Guan

Chinese Academy of Sciences, Kunming Institute of Zoology, Kunming 65024 Yunnan, China

P. Fan

Department of Life Science and Chemistry, Dali University, Dali 671003 Yunnan, China

Present Address:

C. C. Grueter

Department of Primatology, Max Planck Institute for Evolutionary Anthropology,

04103 Leipzig, Germany 
Keywords ape $\cdot$ China $\cdot$ extinction $\cdot$ gibbon $\cdot$ Hylobates lar $\cdot$ Yunnan Province

\section{Introduction}

Yunnan province in southwest China is the hotspot of all Chinese provinces, home to a rich diversity of mammals including primates (Ji and Jiang 2004; Yang et al. 2004; Zhang and Lin 1985). Of the 21 species of primates in China (Zhang et al. 2002), several are listed as endangered on the IUCN Red List of Threatened Species (IUCN 2007, 2009). They have experienced drastic contractions in geographical distribution and reduction in numbers as a result of various forms of exploitation, such as excessive slash and burn cultivation, commercial logging, and hunting (Bleisch 1994; Jiang et al. 2006; Zhang et al. 1981).

Researchers have reported 4 species of gibbons (Hylobatidae) from Yunnan: 1) white-cheeked gibbons (Nomascus leucogenys) had occurred at the extreme south of Yunnan in Xishuangbanna to the east of the Lancangjiang (Mekong), close to the Laotian border (Geissmann et al. 2000; Groves 2001; Ma and Wang 1986), but may now be close to extinction in China (Fan and Huo 2009). 2) Eastern hoolock gibbons (Hoolock leuconedys) are an endangered species that occurs in west Yunnan, e.g., Gaoligongshan Nature Reserve (Lan 1994; Lan and Dunbar 2000). 3) Western black crested gibbons (Nomascus concolor) are distributed in southeast, west, and central Yunnan (Bleisch and Chen 1990). 4) White-handed or lar gibbons (Hylobates lar) were believed to live in a tiny area in southwest Yunnan's Lincang and Simao Prefectures (Ma and Wang 1986). Current knowledge of distribution, population size, and conservation status of these gibbon species in Yunnan is incomplete (Geissmann 2007; Grüter 2005). Here, we focus on lar gibbons in Yunnan.

Lar gibbons occur in Malaysia (throughout most of the Malayan peninsula), Indonesia (northern Sumatra), western and northern Thailand, southern and eastern Myanmar, northwest Laos, and southern China (southwest Yunnan), and researchers have described several local subspecies (Geissmann 1995; Groves 2001). Yunnan lar gibbons (Hylobates lar yunnanenis) of southern China are one such form. Ma and colleagues collected the holotype for this subspecies in 1964 at Lafu in Menglian County, and it is distinguished from other subspecies by its shorter light hair-bases, longer hairs on the back, and dark brown or red brown pubic hairs (Ma and Wang 1986; Ma et al. 1988). Authors of recent taxonomic articles list it as a distinct subspecies, but also state that its recognition as a valid subspecies is still debated (Brandon-Jones et al. 2004; Geissmann 2007). Its supposed distribution range is confined to a small area between the Nujiang (Salween) and Lancangjiang (Mekong) rivers, and represents the northernmost geographic occurrence of Hylobates lar (Li and Lin 1983). Hylobates lar yunnanenis is threatened mainly by habitat loss and is critically endangered (CR; IUCN 2007) or data deficient (IUCN 2009). Haimoff et al. (1987) estimated a maximum of ca. 50-100 groups, a number that is highly speculative given that the species appears to be restricted to lowland areas along rivers that are most affected by habitat destruction and hunting.

The past distribution of lar gibbons within China covered the counties of Cangyuan, Menglian, and Ximeng. By 1995, though, they were thought to be extinct outside Cangyuan (Guo and Wang 1995). At the present time, Nangunhe Nature 
Reserve in Cangyuan is assumed to be the last area of occurrence of this gibbon taxon in China. Before the 1960s there were reportedly "around 200" lar gibbons on both sides of the Nangun River at elevations ranging from 1000 to $1500 \mathrm{~m}$, and local inhabitants reported hearing gibbon calls every morning (Guo and Wang 1995). During a short-time and small-scale census in November 1988, Lan and Wang heard 2 gibbon groups and sighted 1 of them in the nature reserve (Lan 1989; Z-S. Wang, pers. comm.). The estimated size for the entire population size at that time was $\leq 10$ groups. Lan and Wang conducted the most recently published census in 1992 (Lan and Wang 2000). The authors were not able to verify the presence of gibbons inside the reserve, but they employed line transects, which is not a very suitable method for detecting gibbons. In November 1992, Wang conducted the last (and unpublished) survey in the reserve and heard 3 gibbon songs. Based on this evidence, Guo and Wang (1995) estimated the population size to be 3 groups with a total of $c a .10$ individuals. Because no data were available on current existence, status, and population size of lar gibbons in China, the international participants of the 2006 Asian Ape Red List workshop in Phnom Penh (Cambodia) expressed their strong concern about the future of this ape and declared investigation of its status a top priority (Geissmann 2007). Our objective was to conduct a systematic census of Hylobates lar yunnanensis in the poorly known Nangunhe Nature Reserve, the presumed last area where Chinese lar gibbons occurred. We aimed to determine whether these gibbons are still present, to assess their abundance and distribution, and compile a list of factors threatening their survival.

\section{Methods}

\section{Survey Area}

Nangunhe (Nangun River) National Nature Reserve (formerly Cangyuan Game Reserve) lies within Cangyuan Wa Nationality Autonomous County in Lincang Prefecture, southwest Yunnan, close to the border with Myanmar at $c a .23^{\circ} 30^{\prime} \mathrm{N}, 99^{\circ}$ $10^{\prime} \mathrm{E}$ (Fig. 1). It was established as a provincial nature reserve in 1980, and upgraded to a national nature reserve in 1995 (71 km² old part), and extended in 2003 to $c a$. $300 \mathrm{~km}^{2}$. The reserve is situated along the Nangun River, which eventually flows into the Salween, and some of its tributaries. The complex topography is composed of deep valleys and locally sheer cliffs. In the old part of the reserve, which was the focus in our study, the elevation ranges from 520 to $1747 \mathrm{~m}$. Average annual temperature is $21.2^{\circ} \mathrm{C}$, and annual rainfall is $1880 \mathrm{~mm}$ (Lan and Wang 2000). The rainy season (monsoon season) typically lasts from May through October and the dry season from November through April. Rainfall during the dry season accounts for only $11 \%$ of the annual total (Yang and Du 2004). During this survey, minimum temperature during the night was a mean $16.9^{\circ} \mathrm{C}\left(\mathrm{SD} 1.7\right.$, range $\left.15-20^{\circ} \mathrm{C}, n=10\right)$, and maximum temperature during the day was $22.9^{\circ} \mathrm{C}\left( \pm 1.8,20-25^{\circ} \mathrm{C}, n=10\right)$.

Nangunhe is located in the northernmost fringe of the Southeast Asian tropical zone. Researchers have recorded a total of 1885 seed plant species (including subspecies and varieties) at Nangunhe (Yang and Du 2004). Four major vegetation types occur within the boundaries of the reserve: 1) moist evergreen forest (Pometia 


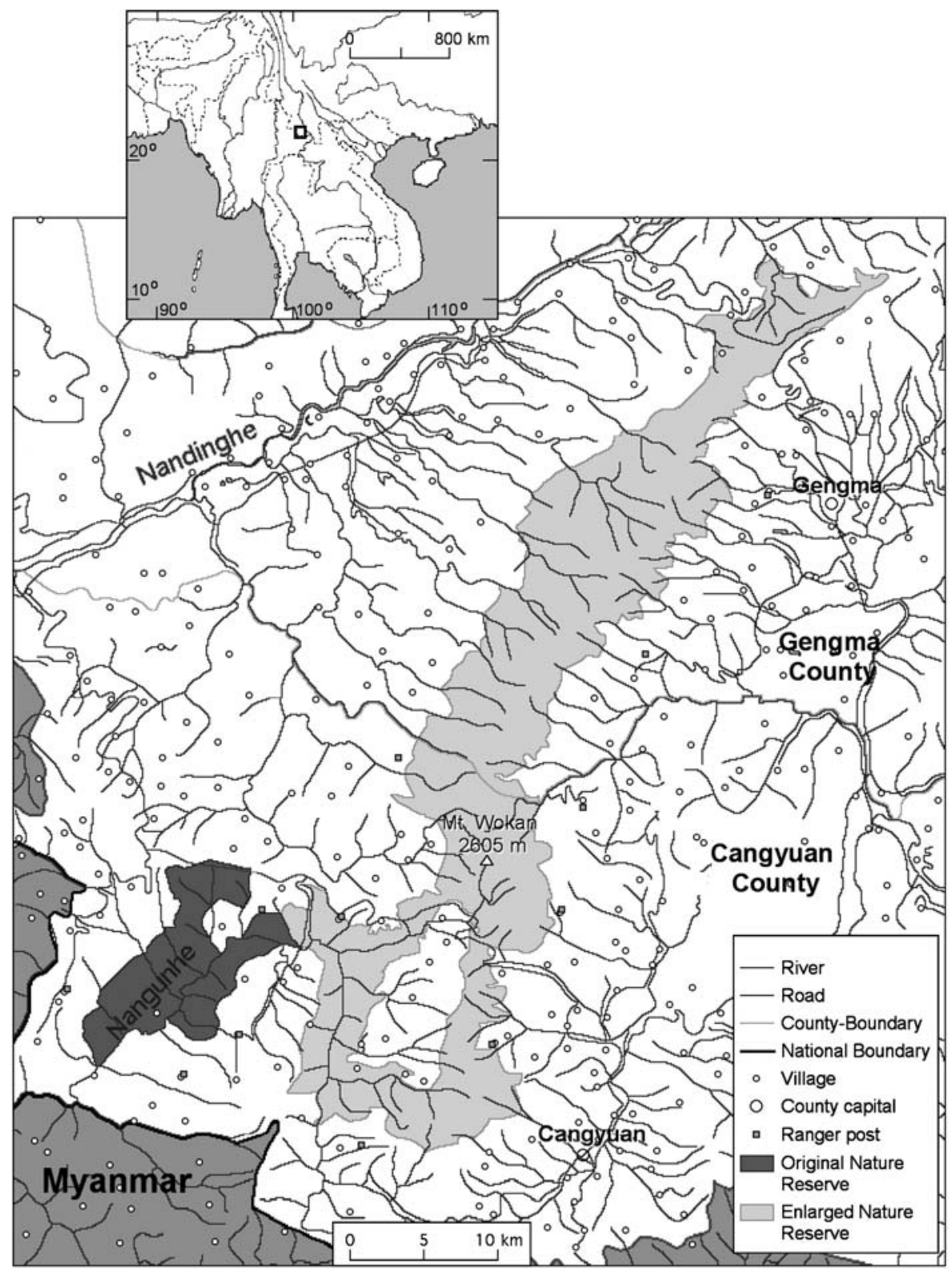

Fig. 1 Map of the original (dark gray) and extended part (light gray) of the Nangunhe Nature Reserve (Geissmann et al. 2006). Inset map: Location of the reserve in Southeast Asia.

tomentosa, Syzygium sp., Tetrameles nudiflora, Terminalia myriocarpa), which is now restricted to steep slopes and along damp foggy river valleys below $800 \mathrm{~m} ; 2$ ) secondary evergreen broad-leaved forest (Cyclobalanopsis sp., Lithocarpus spp., Lindera sp., Castanopsis sp.) on hillsides; 3) subtropical coniferous forest (Pinus kesiya, Calocedrus macrolepis) on mountain ridges; and 4) giant bamboo forest (Dendrocalamus spp.) forming a transitional zone between tropical forest and 
evergreen broadleaf forest. The largest area of the reserve is composed of secondary or succession forest (Lan and Wang 2000; and this study; Fig. 2).

The forest has been gradually replaced by farmland and plantations, resulting in a small island reserve surrounded and invaded by fields and villages (Fig. 3). Deforestation as a means of creating arable land for rubber plantations is still a major threat. The Wa people, the local ethnic minority, living on both sides of the international border, were hunters in the past. Whereas hunting activities have diminished, the reserve is still subject to pressures from shifting cultivation (abandoning a piece of land for 10-12 years after only 1 year of use) practiced by the Wa people (Lai 2000; Zhang et al. 2006).

Yang and Du (2004) catalogued 98 species of mammals in a previous survey at Nangunhe. There are apparently 3-8 tigers (Panthera tigris corbetti) left within the reserve (J-C. Chao, pers. comm.; Anonymous 2002). This is also 1 of the only 2 areas in China (and Yunnan) where Asian elephants (Elephas maximus) occur. Nangunhe Reserve still has ca. 6 herds totalling 16 females and 2 bulls (Y. Li, pers. comm.; Zhang et al. 2006). Previously, the foundation of Nangunhe Reseve, local populations were connected with populations in Myanmar, but by 1980 the corridor had been destroyed by farming and human activities, and the elephant population within the reserve became isolated (Zhang et al. 2006). The resident primate fauna includes the following species: rhesus macaques (Macaca mulatta), Assam macaques (Macaca assamensis), stump-tailed macaques (Macaca arctoides), northern pig-tailed macaques (Macaca leonina), Phayre's leaf monkeys (Trachypithecus phayrei), and Bengal slow lorises (Nycticebus bengalensis) (Yang and Du 2004; this survey). The avifauna is composed of $>150$ species (Yang and Du 2004; this survey.) There are a number of rare and nationally protected birds, such as great hornbills (Buceros bicornis), green peafowls (Pavo muticus), and red-breasted parakeets (Psittacula alexandri). We sighted 11 bird species not recorded previously at Nangunhe. The expanded new part of the Nangunhe Nature Reserve (Fig. 1), stretching from Cangyuan into Gengma County, is one of the last remaining areas in China where black-crested gibbons (Nomascus concolor furvogaster) still occur. They are assumed to inhabit predom-

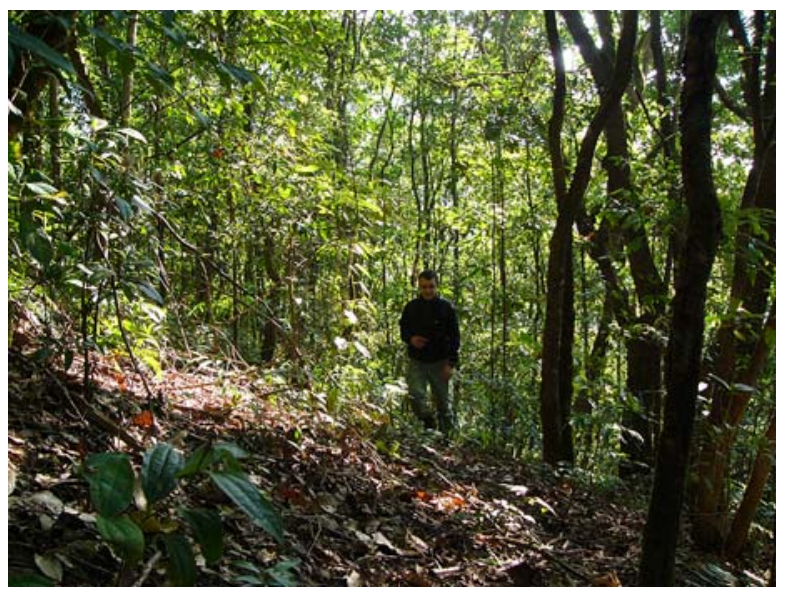

Fig. 2 Extensive tracts of secondary forest characterize the upland areas at Nangunhe Nature Reserve. 


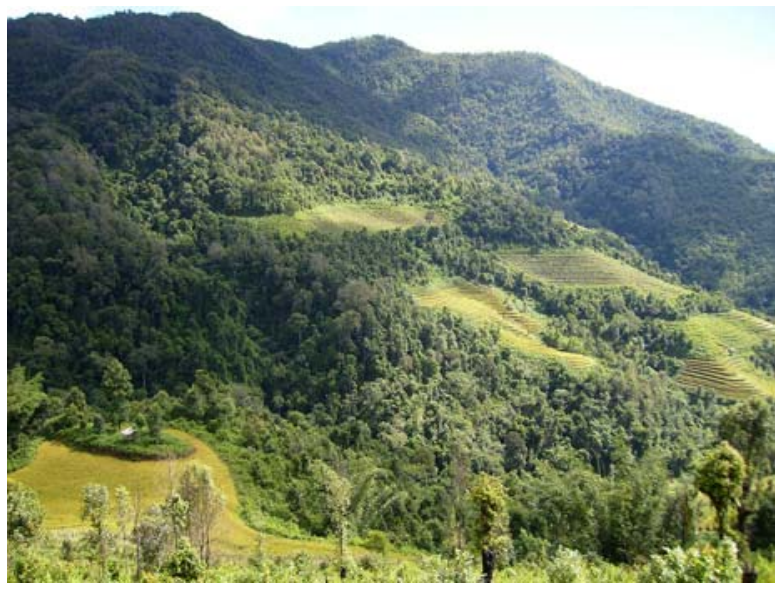

Fig. 3 Much of the gibbons' natural habitat has been converted to farmland.

inantly the subtropical forests in the rugged mountainous terrain around Mt Wokan (2605 m), the highest peak in the area (Haimoff et al. 1987; Lan and Guo 1995). X-L. Jiang (pers. obs.) still heard calls of these gibbons in 1992 Detailed information on population size of the species at Nangunhe is not available.

\section{Survey Procedure}

We surveyed the reserve from November 4 to 18,2007 . We restricted the survey to the old part of the reserve, because lar gibbons have never been recorded from the extension area that encompasses montane terrain that does not represent their habitat. Because gibbons are more often detected aurally than visually, line transects are suboptimal in estimating gibbon densities (Brockelman and Srikosamatara 1993). Brockelman and Srikosamatara (1993) and Brockelman and Ali (1987) have developed methods to monitor loud calls from fixed listening posts. The method has proven to be the most time-efficient technique, cover the largest survey area (Nijman and Menken 2005), and is currently the standard procedure and widely applied in gibbon surveys (Buckley et al. 2006; Geissmann and Nijman 2006; Jiang et al. 2006; Whittaker 2005). Listening posts are prominent topographical spots with good views, such as ridge tops and outcrops from where surveyors monitor gibbon vocal activity for several consecutive days and principally note distance to and direction of the calling gibbon group. We established 18 listening posts at elevations 782-1501 m: 4 in the northern area (circle 1), 11 in the central area (circles 2 and 3), and 3 in the southern area (circle 4) (Table I; Fig. 4). We attempted, whenever the terrain structure allowed, to maintain a distance of 500-1000 m between listening posts. Besides the Swiss and Chinese primatologists, additional surveyors were recruited from the reserve staff and were trained in survey methods and basic gibbon biology before field work. A total of 14 people participated in the survey. One academic and one ranger manned each post. We arrived at listening posts not later than $0600 \mathrm{~h}$ and stayed there until $c a 1100 \mathrm{~h}$. We prepared a check sheet that included the following information: geographical coordinates of listening posts 


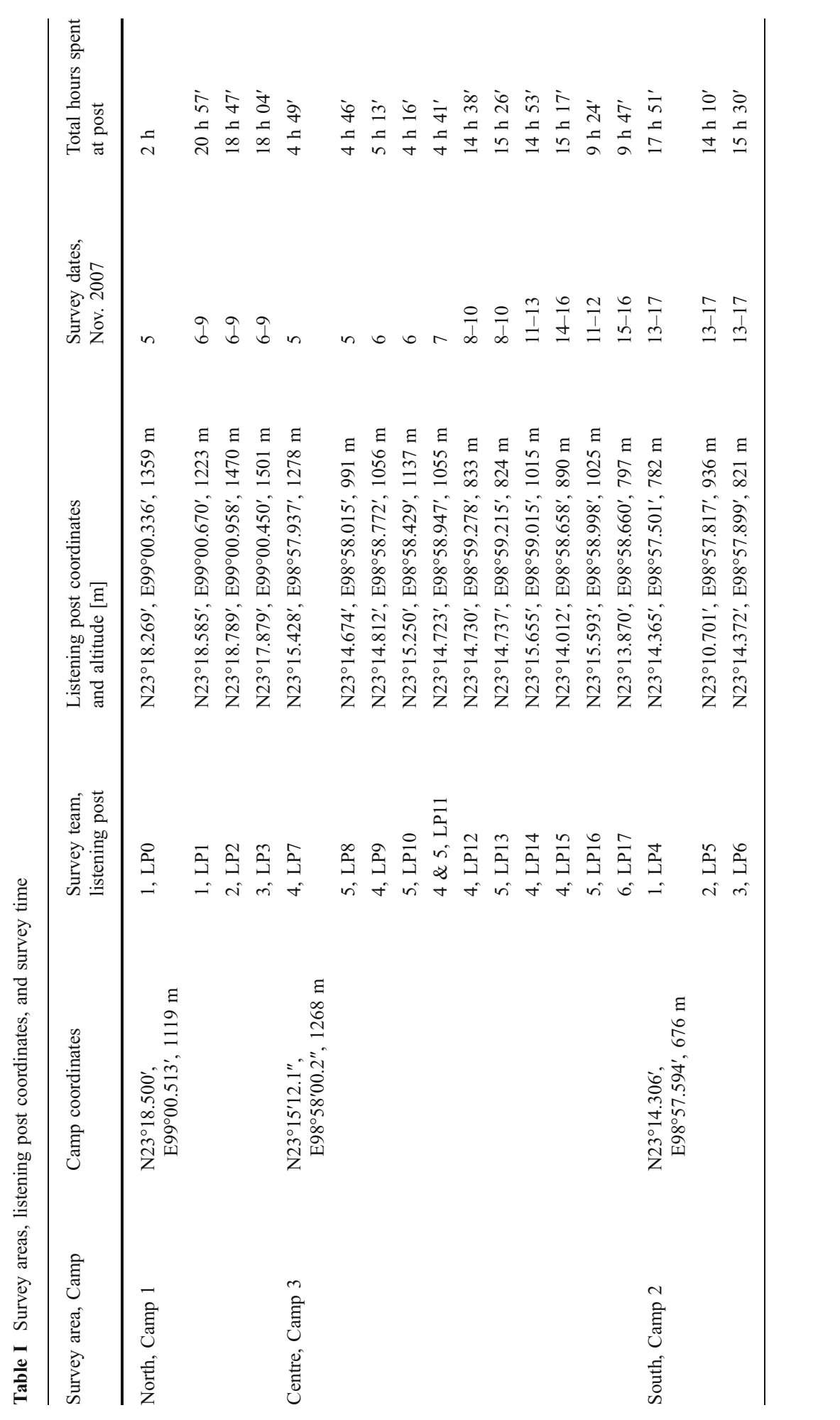




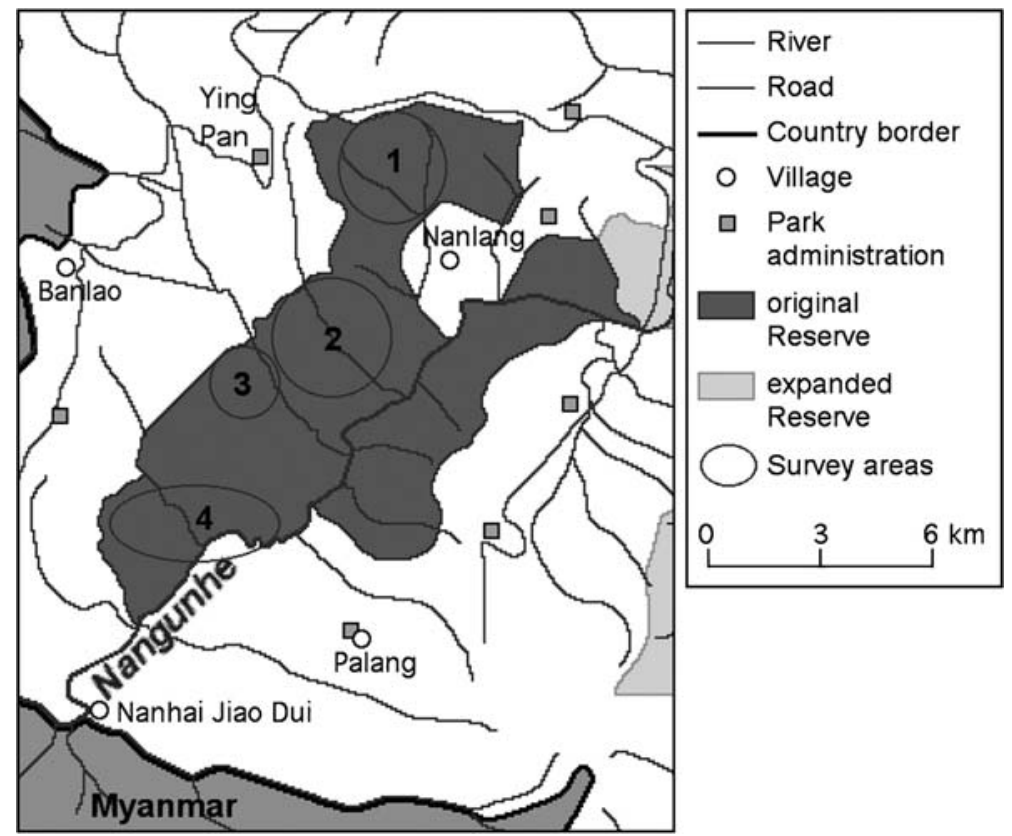

Fig. 4 Map showing the surveyed areas within the original part of the Nangunhe Nature Reserve. Circle 1 denotes the northern area, circles 2 and 3 the middle area, and circle 4 the southern area.

(using GPS receivers), altitude, date, and time of arrival at and departure from the observation post.

In addition, we conducted informal interviews in adjacent villages to help identify potential areas of current gibbon distribution and reconstruct former gibbon occurrence. During the surveys, we also compiled evidence of the current degree of human encroachment (wood cutting, poaching, resource harvesting, etc.) inside the reserve. We also took opportunistic records of the presence of birds and mammals at the reserve, as evidenced by sightings, aural cues, and tracks and prints.

\section{Results}

We surveyed 3 main sectors of the old reserve known to have supported gibbons in the past: the northern tip, where local inhabitants heard gibbons in ca. 1999 (Table II); the central core area around Papeng, where guides recall having heard gibbons frequently in the mid-1990s; and the southern buffer zone, where gibbons were present until the early 1980s according to local informants. Pristine primary forest is now present only in very small fragments, and we surveyed all potential gibbon habitats with remaining patches of primary forests. We were unable to confirm the presence of lar gibbons inside the reserve. We recorded neither duets nor solo songs during this survey. Whereas interviewees familiar with the northern parts of the reserve usually remembered gibbons and were able to describe them correctly, interviewees from the southern parts of the reserve were mostly unfamiliar with gibbons. 


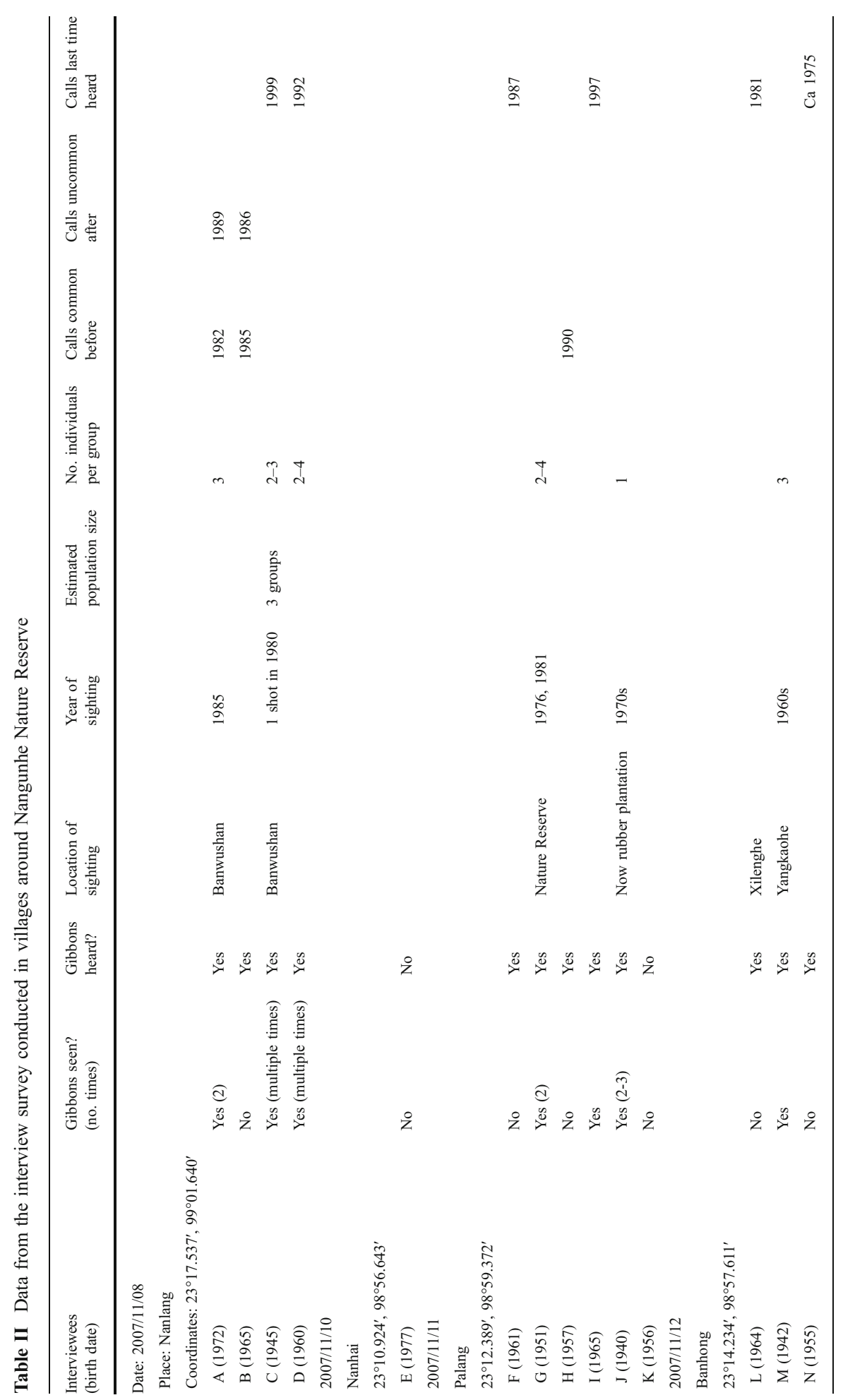


Our reconnaissance surveys of the forest show that most of the plant communities are still in a successional process, and cursory inspections of tree stems and crowns indicate that the height of trees in secondary forest is substantially smaller than that of trees in primary forest and that the canopy is relatively open. Tree-species diversity also seems to be considerably lower in the secondary forest. The regenerating secondary forest does not appear to be suitable habitat for gibbons, owing to the lack of preferred food/fruit trees and vines and an unbroken canopy for their strictly arboreal way of locomotion.

The number of people living inside the reserve seems to be low. We did not encounter any people in the central area of the reserve, and 2 villages within the reserve had been relocated in the late 1980s. It was evident that human perturbation is ongoing: in the northern part of the nature reserve, we heard gunshots and the noise of a chainsaw, but they may have come from outside the reserve boundary; we encountered grazing cattle and cattle dung in various places; and we discovered an abandoned campsite. In the central part of the reserve, we sighted a hunters' hideout.

\section{Discussion}

In a 2-week field survey with 6survey teams, we found no visual or auditory evidence of lar gibbons still living at Nangunhe. The fact that none of the local rangers has heard gibbons for about a decade supports our conclusion that they no longer occur at Nangunhe.

It is of course possible that some lar gibbons still occur at Nangunhe and remained undetected during our survey, but the chance of this is extremely low. Given that the size of the reserve is relatively small and gibbon calls can travel as far as $c a$. 1-2 km, it is unlikely that they called without being detected. Lack of singing in an area does not necessarily mean that no gibbons are present (Brockelman and Srikosamatara 1993). Gibbon groups are known to cease calling during inclement weather (Brockelman and Srikosamatara 1993), so prolonged rainy periods may result in an underestimation of gibbon density. The absence of gibbon calls during our field study cannot be attributed to bad weather, however, as we met dry and sunny weather conditions almost every morning of the survey, i.e., during the gibbons' preferred calling time. Previous surveys (in 1988 and 1992) were conducted in November, during which gibbon calls were heard (Z. Wang, pers. comm.). Moreover, 2 local villagers reported in interviews that the singing activity of lar gibbons was usually very high in November and early winter. Calling frequency is also influenced by the density of gibbons in an area, with groups at lower densities calling less, sometimes not calling for days despite favorable weather (Cheyne 2008; Chivers 1974). Thus, gibbon groups in disturbed areas with a decimated population, e.g., by hunting, may call much less than those in undisturbed areas (Brockelman and Srikosamatara 1993). Nevertheless, the fact that not a single call was recorded during the 2-week survey indicates the absence of gibbons.

Even if a few individuals remained unnoticed, it is highly unlikely that these would constitute a viable population. Although the reasons for the disappearance of lar gibbons in China are not entirely clear, it appears that large-scale destruction of primary forests (suitable habitat) in the 1960s and 1970s has brought about an initial 
decline in numbers, and subsequent uncontrolled hunting has resulted in their extirpation.

Most of the plant communities are regenerating from past destruction, and the abundant young-growth trees of the secondary forest do not provide suitable resources and habitat for gibbons. Whereas other flagship species at Nangunhe, i.e., Asian elephants and tigers, are able to cope with altered habitat to some extent, gibbons are far less adaptable and strictly dependent on primary forest rich in fleshy fruit resources (Palombit 1997), a continuous canopy that permits them to exhibit their typical swinging locomotion (Carpenter 1976) and old-growth trees that offer stable sleeping sites (Reichard 1998). Forest destruction has largely resulted from an expansion of past slash-and-burn agriculture and current rubber plantations. Nangunhe Reserve still suffers from degradation at the periphery.

We found clear signs that human perturbations are still prevalent inside the nature reserve. Gibbons are traditionally hunted for the purpose of selling their medicinally valuable body parts, the pet trade, and food (Geissmann 2003). Gibbons are an easy target because of their characteristic behavioral traits; their conspicuous far-reaching calls and strict territoriality (Gittins and Raemaekers 1980) make detecting and locating them straightforward. Wildlife protection laws may have acted only marginally as deterrents and not have prevented opportunistic hunting. Lack of funds, human resources, and capacity at the Nangunhe Nature Reserve may have hampered proper implementation of conservation actions. Lar gibbons may have already been at the brink of extinction when the reserve was set up, and it is likely that only effective patrolling and surveillance would have saved them from being targeted by hunters. In addition, the ruggedness of the terrain may have discouraged reserve staff from monitoring the less accessible parts in the core zone and may have provided conditions for poachers to operate unimpeded.

The loss of the lar gibbon has seriously reduced the value of the reserve as a biodiversity conservation area, as well as an area of ecotourism potential, but it remains of regional importance because of the rich biota, including threatened mammals, such as tigers and elephants. Removal of a large primate species negatively affects ecosystem health because gibbons occupy a key role in a forest community as seed dispersers and potential prey for predators ( $c f$. Jernvall and Wright 1998; McConkey 2000; Uhde and Sommer 2002).

According to the IUCN definitions, a taxon is "presumed extinct when exhaustive surveys in known and/or expected habitat, at appropriate times (diurnal, seasonal, annual), throughout its historic range have failed to record an individual. Surveys should be over a time frame appropriate to the taxon's life cycle and life form." Using this definition, it is premature to declare the lar gibbon as extinct in China, as 2 other localities (Menglian, Ximeng) within the historical range were not surveyed. However, chances are minimal that they still exist in the unprotected areas of Menglian and Ximeng counties, given that the protected population of the reserve has vanished. The forest in Lafu, Menglian, where the type specimen of Hylobates lar yunnanesis was collected, was converted into rubber plantations, and no evidence of gibbons was found during a brief visit to Menglian in 1994 (X.-L. Jiang, Y.-X. Wang, pers. obs.). It is not known whether Hylobates lar yunnanensis also occurs in adjacent regions of Myanmar, for which data on forest distribution are lacking. Owing to the closeness to the border of Myanmar, we were able to obtain an 
overview of the border landform types: agricultural fields and rubber plantations are rampant, and we spotted no potential gibbon habitat. Moreover, there is no reported protected area adjacent on the Myanmar side, but, for an unambiguous conclusion regarding the extinction of Hylobates lar yunnanensis, it is necessary to inspect the locations in greater detail. Owing to these persisting ambiguities, we conclude that lar gibbons are presumed extinct in China. It remains unclear whether Hylobates lar yunnanensis still survives or not, because the status of the taxon in Myanmar, if it ever occurred there in the first place, is data deficient. Hylobates lar yunnanensis is also not known from any zoological gardens.

Our survey results strongly suggest that lar gibbons are no longer part of the Chinese mammalian fauna. With 6 species present in recent times, the gibbon diversity of China is exceptional (and topped only by Indonesia), but the situation for the Chinese gibbons is nothing less than disastrous, with 4 species facing extinction. Hylobates lar is now presumed to have become extinct during the last few years. There is no record of Nomascus leucogenys since the 1980s, when a small population still occurred in Mengla and Shangyong Nature Reserve in southernmost Yunnan (Bleisch and Zhang 2004; Hu et al. 1989, 1990; Yang et al. 1985). A recent interview survey has shown that there is a slight possibility of a remnant population still existing in these reserves, but that it is more likely that the species is nearly extinct or already extinct in China (Fan and Huo 2009), Nomascus hainanus and $N$. nasutus are at the brink of extinction, with $<20$ and $c a 110$ individuals remaining, respectively (Chan et al. 2005; Foges 2008; Geissmann et al. 2002, Geissmann $2005 \mathrm{a}, \mathrm{b}$ ). The latter 3 taxa belong to a genus (crested gibbons) whose historic range stretched over an extensive area in southern China, from the Three Gorges to Hainan Island (Gao et al. 1981; Geissmann et al. 2000; van Gulik 1967). Lar gibbons, conversely, may have only slightly ranged into China, as their main distribution area lies within Southeast Asia. Fortunately, Hylobates lar as a whole is not threatened with extinction, but densities are declining where protection personnel do not patrol. Conservation measures should be initiated to ensure the survival of the still-thriving populations.

Acknowledgments Backup from the Forestry Department of Yunnan Province made this survey possible. Staff members and rangers of the Nangunhe NR, including Chen Haibin, Feng Caozhong, Wang Zhisheng, Xiong Youming, Yang Hongwei, Yang Hongqiang, Zhao Jinchao, and Zhong Ming, provided field assistance. We thank 2 anonymous reviewers for providing helpful comments on the manuscript. The Nando Peretti Foundation, the Gibbon Conservation Alliance, G. \& A. Claraz-Schenkung, and the Jane Goodall Institute, Switzerland provided financial support for this survey.

Open Access This article is distributed under the terms of the Creative Commons Attribution Noncommercial License which permits any noncommercial use, distribution, and reproduction in any medium, provided the original author(s) and source are credited.

\section{References}

Anonymous. (2002). Traces of Bengal tigers found in Yunnan Province. Xinhua News Agency, January 24, 2002. Retrieved from http://french.hanban.edu.cn/english/TR-e/25766.htm.

Bleisch, W. (1994). Wildlife conservation in China: the problem of priorities. Chinese Biodiversity, 2, 47-54. 
Bleisch, W., \& Chen, N. (1990). Conservation of the black-crested gibbon in China. Oryx, 24, 147156.

Bleisch, W., \& Zhang, Y. (2004). The view accross the border: China and the future of Vietnamese primates. In T. Nadler, U. Streicher \& Ha Thang Long (Eds.), Conservation of primates in Vietnam (pp. 107-114). Hanoi: Frankfurt Zoological Society, Vietnam Primate Conservation Programme, Endangered Primate Rescue Center, Cuc Phuong National Park.

Brandon-Jones, D., Eudey, A. A., Geissmann, T., Groves, C. P., Melnick, D. J., Morales, J. C., et al. (2004). Asian primate classification. International Journal of Primatology, 25, 97-164.

Brockelman, W. Y., \& Ali, R. (1987). Methods of surveying and sampling forest primate populations. In C. W. Marsh \& R. A. Mittermeier (Eds.), Primate conservation in the tropical rain forest (pp. 23-62). New York: Alan R. Liss.

Brockelman, W. Y., \& Srikosamatara, S. (1993). Estimation of density of gibbon groups by use of loud songs. American Journal of Primatology, 29, 93-108.

Buckley, C., Nekaris, K. A. I., \& Husson, S. J. (2006). Survey of Hylobates agilis albibarbis in a logged peat-swamp forest: Sabangau catchment, Central Kalimantan. Primates, 47, 327-335.

Carpenter, C. R. (1976). Suspensory behaviour of gibbons (Hylobates lar): a photoessay. In D. N. Rumbaugh (Ed.), Gibbon and siamang (pp. 1-20). Basel: Karger.

Chan, B. P. L., Fellowes, J. R., Geissmann, T., \& Zhang, J. (2005). Hainan gibbon status survey and conservation action plan, version 1 (last updated November 2005). Hong Kong: Kadoorie Farm \& Botanic Garden Technical Report No. 3, Kadoorie Farm \& Botanic Garden.

Cheyne, S. M. (2008). Effects of meteorology, astronomical variables, location and human disturbance on the singing apes: Hylobates albibarbis. American Journal of Primatology, 70, 386-392.

Chivers, D. J. (1974). The siamang in Malaya: a field study of a primate in tropical rainforest. Basel: Karger.

Fan, P.-F., \& Huo, S. (2009). The northern white-cheeked gibbon (Nomascus leucogenys) is on the edge of extinction in China. Gibbon Journal, 5, 44-52.

Foges, R. (2008). World's rarest ape numbers double after FFI survey. Press release. Cambridge: Fauna \& Flora International [http://www.fauna-flora.com/docs/cao_vit_media_release.pdf].

Gao, Y., Wen, H., \& He, Y. (1981). The change of historical distribution of Chinese gibbons (Hylobates). Zoological Research, 2, 1-8. (Chinese text, English summary).

Geissmann, T. (1995). Gibbon systematics and species identification. International Zoo News, 42, 467501.

Geissmann, T. (2003). Symposium on gibbon diversity and conservation: concluding resolution. Asian Primates, 8, 28-29.

Geissmann, T. (2005a). Auf der Suche nach den letzten Gibbons von Hainan. Gibbon Journal, 1, 18-22. (German text, English summary).

Geissmann, T. (2005b). Der Hainan-Schopfgibbon: Der bedrohteste Menschenaffe der Welt. Gibbon Journal, 1, 10-12. (German text, English summary).

Geissmann, T. (2007). Status reassessment of the gibbons: results of the Asian Primate Red List Workshop 2006. Gibbon Journal, 3, 5-15.

Geissmann, T., \& Nijman, V. (2006). Calling in wild silvery gibbons (Hylobates moloch) in Java (Indonesia): behavior, phylogeny, and conservation. American Journal of Primatology, 68, 1-19.

Geissmann, T., Nguyen, X. D., Lormée, N., \& Momberg, F. (2000). Vietnam primate conservation status review 2000 - Part 1: gibbons (English edition). Hanoi: Fauna \& Flora International, Indochina Programme.

Geissmann, T., La Quang Trung, Trinh Dinh Hoang, Dang Ngoc Can, Pham Duc Tien, \& Vu Dinh Thong (2002). Report on an overall survey of the Cao Vit gibbon population (Nomascus sp. cf. nasutus) in Trung Khanh District, Cao Bang Province (second overall survey). Unpublished survey report. Hanoi: Fauna \& Flora International, Asia Pacific Programme.

Geissmann, T., Traber, S., \& von Allmen, A. (2006). Das Nangunhe-Naturreservat, Provinz Yunnan, China: Ein Projektbericht [Nangunhe Nature Reserve, Yunnan Province, China: a project report]. Gibbon Journal, 2, 14-17. (German text, English summary).

Gittins, S. P., \& Raemaekers, J. J. (1980). Siamang, lar and agile gibbons. In D. J. Chivers (Ed.), Malayan forest primates: ten years'study in tropical rain forest (pp. 63-105). New York: Plenum Press.

Groves, C. P. (2001). Primate taxonomy. Washington, DC: Smithsonian Institution Press.

Grüter, C. C. (2005). Der Nanguanhe-Regenwald im Südwesten Chinas: Eines der letzten Rückzugsgebiete für chinesische Gibbons. Gibbon Journal, 1, 13-14. (German text, English summary).

Guo, G., \& Wang, Z. (1995). Survey on the whitehanded gibbon in Nangunhe valley in China. Chinese Primate Research and Conservation News, 4, 7-9. 
Haimoff, E. H., Yang, X.-J., He, S.-J., \& Chen, N. (1987). Conservation of gibbons in Yunnan Province, China. Oryx, 21, 168-173.

Hu, Y., Xu, H. L., \& Yang, D. (1989). The studies on ecology in Hylobates leucogenys. Zoological Research, 10((Supplement)), 61-67. (Chinese text, English summary).

Hu, Y., Xu, H., \& Yang, D. (1990). Feeding ecology of the white-cheeked gibbon (Hylobates concolor leucogenys). Acta Ecologica Sinica, 10, 155-159. (Chinese text, English summary).

IUCN. (2007). IUCN Red List of Threatened Species. IUCN, Gland, Switzerland. Retrieved from http:// www.iucnredlist.org (Accessed 22 December 22, 2007).

IUCN. (2009). IUCN Red List of Threatened Species. IUCN, Gland, Switzerland. Retrieved from http:// www.iucnredlist.org (Accessed June 15, 2009).

Jernvall, J., \& Wright, P. C. (1998). Diversity components of impending primate extinctions. Proceedings of the National Academy of Sciences, 95, 11279-11283.

Ji, W., \& Jiang, X. (2004). Primatology in China. International Journal of Primatology, 25, 1077-1092.

Jiang, X., Luo, Z., Zhao, S., Li, R., \& Liu, C. (2006). Status and distribution pattern of black crested gibbon (Nomascus concolor jingdongensis) in Wuliang Mountains, Yunnan, China: implication for conservation. Primates, 47, 264-271.

Lai, Q. (2000). Community forestry and conflict management: A case in Nangun River Nature Reserve, Yunnan, China. Downloaded on 27 March 2009 from: www.mekonginfo.org/mrc_en/doclib.nsf/0/ 6017CDBE3CFDD122472568E1001397B1/\$FILE/FULLTEXT.html.

Lan, D. (1989). Preliminary study on the group composition, behavior and ecology of the black gibbons (Hylobates concolor) in Southwest Yunnan. Zoological Research, 10((Supplement)), 119-126. (Chinese text, English summary).

Lan, D. (1994). Progress of surveys of hoolock gibbon in Yunnan: distribution, population size, habitat and conservation. Chinese Primate Research and Conservation News, 3, 8-10.

Lan, D., \& Dunbar, R. (2000). Bird and mammal conservation in Gaoligongshan region and Jingdong county, Yunnan, China: patterns of species richness and nature reserves. Oryx, 34, 275-286.

Lan, D., \& Guo, G. (1995). Present status on conservation of primates in Lincang district of Yunnan. Chinese Primate Research and Conservation News, 4, 4-7.

Lan, D., \& Wang, Z. (2000). Wildlife conservation in Nanguanhe River Nature Reserve: a preliminary survey. TigerPaper, 27, 24-28.

Li, Z., \& Lin, Z. (1983). Classification and distribution of living primates in Yunnan, China. Zoological Research, 4, 111-120. (Chinese text, English summary).

Ma, S., \& Wang, Y. (1986). The taxonomy and distribution of the gibbons in southern China and its adjacent region - with description of three new subspecies. Zoological Research, 7, 393-410. (Chinese text, English summary).

Ma, S. L., Wang, Y. X., \& Poirier, F. E. (1988). Taxonomy, distribution and status of gibbons (Hylobates) in southern China and adjacent areas. Primates, 29, 277-286.

McConkey, K. R. (2000). Primary seed shadow generated by gibbons in the rain forests of Barito Oulu, central Borneo. American Journal of Primatology, 52, 13-29.

Nijman, V., \& Menken, S. B. J. (2005). Assessment of census techniques for estimating density and biomass of gibbons (Primates: Hylobatidae). Raffles Bulletin of Zoology, 53, 169-179.

Palombit, R. A. (1997). Inter- and intraspecific variation in the diets of sympatric siamang (Hylobates syndactylus) and lar gibbon (Hylobates lar). Folia Primatologica, 68, 321-337.

Reichard, U. (1998). Sleeping sites, sleeping places, and presleep behavior of gibbons (Hylobates lar). American Journal of Primatology, 46, 35-62.

Uhde, N. L., \& Sommer, V. (2002). Antipredatory behavior in gibbons (Hylobates lar, Khao Yai/ Thailand). In L. E. Miller (Ed.), Eat or be eaten: predator sensitive foraging among primates (pp. 268291). New York: Cambridge University Press.

van Gulik, R. H. (1967). The gibbon in China. An essay in Chinese animal lore. Leiden: E. J. Brill.

Whittaker, D. J. (2005). New population estimates for the endemic Kloss's gibbon Hylobates klossii on the Mentawai Islands, Indonesia. Oryx, 39, 458-461.

Yang, Y., \& Du, F. (eds). (2004). Nangun River National Nature Reserve of China. Kunming: Yunnan Science and Technology Press.

Yang, Y., Tian, K., Hao, J., Pei, S., \& Yang, Y. (2004). Biodiversity and biodiversity conservation in Yunnan, China. Biodiversity and Conservation, 13, 813-826.

Yang, D., Zhang, J., \& Li, C. (1985). A survey report on the number and distribution of gibbons in Yunnan. Medical Biological Research, 3, 22-27. (in Chinese).

Zhang, Y. Z., \& Lin, Y. L. (1985). The distribution tendency of land mammals in China and adjacent areas. Acta Zoologica Sinica, 31, 187-197. (in Chinese with English abstract). 
Zhang, Y.-Z., Wang, S., \& Quan, G.-Q. (1981). On the geographical distribution of primates in China. Journal of Human Evolution, 10, 215-226.

Zhang, Y., Chen, L., Qu, W., \& Coggins, C. (2002). The primates of China: biogeography and conservation status Past, present and future. Beijing: China Forestry Publishing House.

Zhang, L., Ma, L., \& Feng, L. (2006). New challenges facing traditional nature reserves: Asian elephant (Elephas maximus) conservation in China. Integrative Zoology, 1, 179-187. 